\title{
Distribution Trend of the Bottom Water at the Bay Mouth of Jiaozhou Bay
}

\author{
Dongfang Yang ${ }^{1,2,3}$, Haoyuan Ren ${ }^{1}$, Dong Yang ${ }^{1}$, Haixia Li ${ }^{1}$, Jing Fang ${ }^{1}$ \\ ${ }^{1}$ Accountancy Shool, Xijing University, Xian 710123, China; \\ ${ }^{2}$ North China Sea Environmental Monitoring Center, SOA, Qingdao 266033, China; \\ ${ }^{3}$ College of Geography and Environmental Science, Tianjin Normal University, Tianjin 300387, China;
}

\begin{abstract}
Based on the survey data of Jiaozhou Bay in May, June, July, August, September and October of 1980, the bottom water temperature and its horizontal distribution in Jiaozhou Bay were studied. The results showed that the bottom water temperature in Jiaozhou Bay ranged at a high level between $12.35^{\circ} \mathrm{C}$ to $25.72{ }^{\circ} \mathrm{C}$ and a low level between $10.18^{\circ} \mathrm{C}$ to $24.58{ }^{\circ} \mathrm{C}$ in May, June, July, August, September and October. From May to October, the bottom water temperature in Jiaozhou Bay was moderately high. In May, June, July and August, a high temperature zone formed around the water inside the bay mouth, and the bottom water temperature reached $12.35^{\circ} \mathrm{C}$ to $25.72^{\circ} \mathrm{C}$. From May to August, the bottom water temperature first increased in the waters inside the bay mouth, followed by the water at the bay mouth, with the water outside the bay mouth as the end. In September and October, the temperature of the eastern coastal water outside Jiaozhou Bay ranged from $20.00^{\circ} \mathrm{C}$ to $24.43^{\circ} \mathrm{C}$, and a high temperature zone formed around there. From September to October, the bottom water temperature first decreased in the water inside the bay mouth, followed by the water at the bay mouth, with the water outside the bay mouth as the end. According to Yang Dongfang's definition of "Cryogenic Low Water Mass", a cryogenic water mass formed in the bottom water at the bay mouth in September and extended widely among the water inside the bay mouth-at the bay mouth-in the southern part outside the bay mouth with a temperature of $23.79^{\circ} \mathrm{C}$ to $23.91^{\circ} \mathrm{C}$.
\end{abstract}

\section{Introduction}

In recent years, disasters such as global warming, sandstorms, floods, storm surges and red tides have occurred frequently, seriously threatening the development of human society and the safety of life and property. For the purpose of disaster prevention and mitigation, people have been increasingly interested in marine ecology, and they pay close attention to terrestrial ecosystem, marine ecosystem and atmospheric ecosystem ${ }^{[1]}$. The temperature along the Qingdao Coastal Area is synchronized with that of the whole world, and has its own characteristics. The average surface temperature rises steadily and the range is large, which is three times as large as that of the whole world ${ }^{[2]}$. Atmosphere temperature and water temperature have strong effects on plants, animals, microorganisms and human body ${ }^{[3-9]}$. Therefore, it is of vast benefit to carry on a study on water temperature variation, high temperature waters and cryogenic water masses in the offshore areas for marine environment protection and ecological sustainable development.

Based on the investigation data in 1980, this paper analyzed the bottom water temperature in Jiaozhou Bay, together with its horizontal distribution and the variation of the source. And there is a study on the bottom water temperature of Jiaozhou Bay, its variation trend and cryogenic water mass, which provides the scientific background for a comprehensive analysis of the heat source of the bottom water in Jiaozhou Bay, the high temperature zone and the cryogenic water mass and a theoretical basis for the bottom water temperature variation and its impact on the environment.

\section{Materials and Methods Used in Water Investigation,}

\subsection{Natural Environment of Jiaozhou Bay}

Located in the southern part of Shandong Peninsula, between $120^{\circ} 04^{\prime} \sim 120^{\circ} 23^{\prime} \quad \mathrm{E}$ and $35^{\circ} 58^{\prime} \sim 36^{\circ} 18^{\prime} \mathrm{N}$, Jiaozhou Bay is a typical semi-enclosed bay with an area of $446 \mathrm{~km} 2$ and an average water depth of $7 \mathrm{~m}$. With the line between Tuan Island and Xuejia Island as the boundary, Jiaozhou Bay is adjacent with the Yellow Sea. There are more than a dozen seagoing rivers in Jiaozhou Bay, among which Dagu River and Yanghe River is of larger runoff amount and silt content, Haibo River, Licun River and Loushan River in Qingdao City belong to seasonal stream and show hydrological characteristics varying with seasonal changes ${ }^{[11,12]}$. 


\subsection{Materials and Methods}

The data of water temperature of Jiaozhou Bay in May, June, July, August, September and October 1980 were provided by the North China Sea Monitoring Center, the State Oceanic Administration. Water samples were taken from eight stations set in Jiaozhou Bay in May, June, July, August, September and October respectively and were marked as H34, H35, H36, H37, H38, H39, H40, H41 and H82 (Fig. 1). When the water depth is more than $10 \mathrm{~m}$, it is supposed to take samples from the surface layer and bottom layer; when it is less than $10 \mathrm{~m}$, it is supposed to take from the surface layer only. This is the national standard method of sampling included in the national document "The Specification for Marine Monitoring" (1991)) ${ }^{[13]}$.

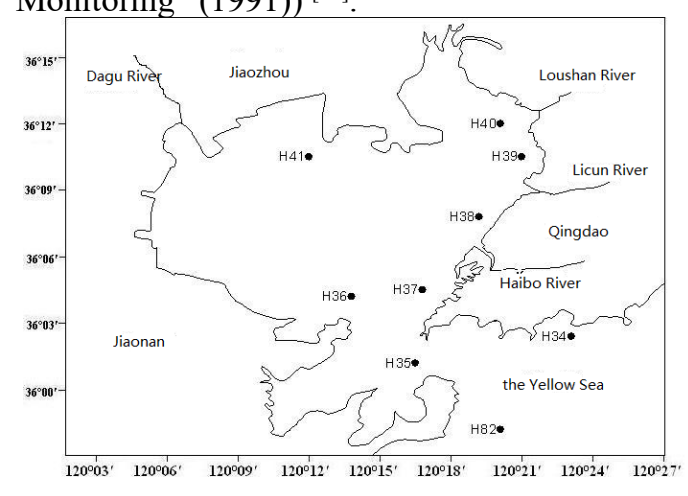

Fig. 1 Survey Stations in Jiaozhou Bay

\section{Results}

\subsection{Bottom Water Temperature}

From May to October, the bottom water temperature in Jiaozhou Bay ranged at a high level between $12.35^{\circ} \mathrm{C}$ to $25.72^{\circ} \mathrm{C}$ and a low level between $10.18^{\circ} \mathrm{C}$ to $24.58^{\circ} \mathrm{C}$, which indicated that the general temperature variation range was $10.18^{\circ} \mathrm{C}$ to $25.72^{\circ} \mathrm{C}$. It also indicated that the temperature of the bottom of the seawater reached above $10.00^{\circ} \mathrm{C}$ and the bottom water temperature of Jiaozhou Bay was relatively high during this period.

\subsection{Horizontal Distribution in the Bottom Layer}

In May, high temperature $12.35^{\circ} \mathrm{C}$ appeared at Station H36 in the water inside the bay mouth of Jiaozhou Bay, and a high temperature zone formed around there with a series of parallel lines of different gradients extending from the water inside the bay mouth to the water outside the bay mouth. The high temperature $12.35^{\circ} \mathrm{C}$ at the center decreased to $10.18^{\circ} \mathrm{C}$ in the water outside the bay mouth of the southern Bay with the change of gradient (Fig. 2).

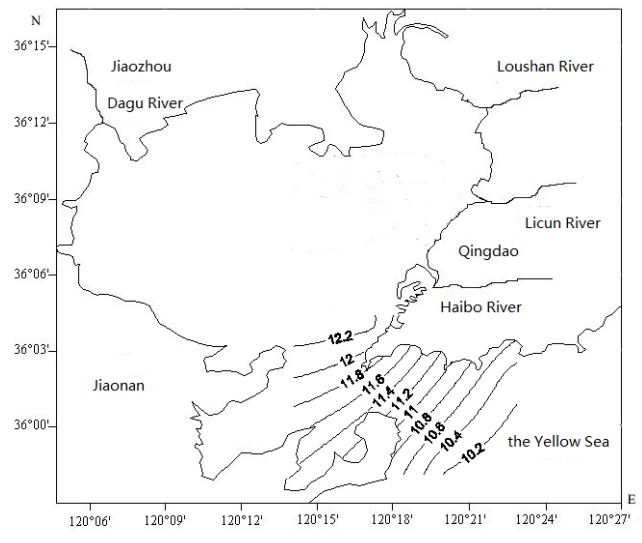

Fig.2 Temperature in the bottom water of Jiaozhou Bay in May $1980\left({ }^{\circ} \mathrm{C}\right)$

In June, high temperature $18.77{ }^{\circ} \mathrm{C}$ appeared at Station H37 in the water inside the bay mouth of Jiaozhou Bay, and a high temperature zone formed around there with a series of parallel lines of different gradients extending from the water inside the bay mouth to the water outside the bay mouth. The high temperature $18.77^{\circ} \mathrm{C}$ at the center decreased to $15.09^{\circ} \mathrm{C}$ in the water outside the bay mouth of the southern Bay with the change of gradient (Fig. 3).

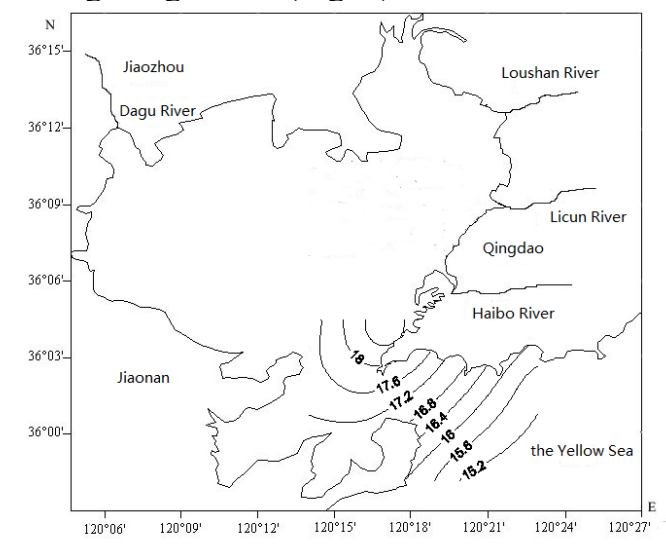

Fig.3 Temperature in the bottom water of Jiaozhou Bay in June $1980\left({ }^{\circ} \mathrm{C}\right)$

In July, high temperature $20.49^{\circ} \mathrm{C}$ appeared at Station H36 in the water inside the bay mouth of Jiaozhou Bay, and a high temperature zone formed around there with a series of parallel lines of different gradients extending from the water inside the bay mouth to the water outside the bay mouth. The high temperature $20.49^{\circ} \mathrm{C}$ at the center decreased to $18.67^{\circ} \mathrm{C}$ in the water outside the bay mouth of the southern Bay with the change of gradient (Fig. 4). 


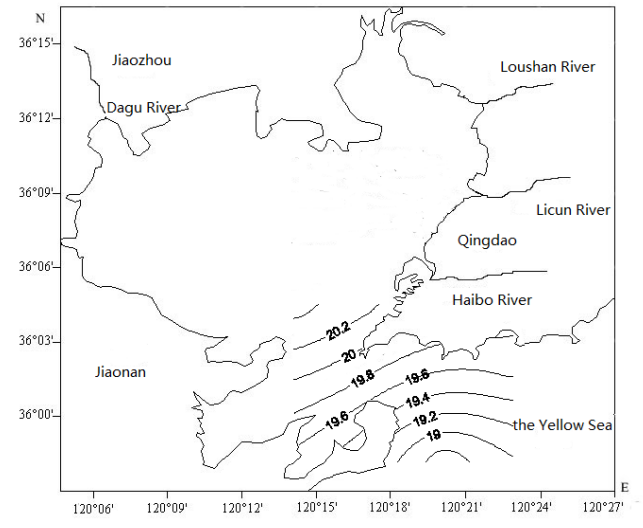

Fig.4 Temperature in the bottom water of Jiaozhou Bay in July $1980\left({ }^{\circ} \mathrm{C}\right)$

In August, high temperature $25.72{ }^{\circ} \mathrm{C}$ appeared at Station H36 in the water inside the bay mouth of Jiaozhou Bay, and a high temperature zone formed around there with a series of parallel lines of different gradients extending from the water inside the bay mouth to the water outside the bay mouth. The high temperature $25.72^{\circ} \mathrm{C}$ at the center decreased to $24.58^{\circ} \mathrm{C}$ in the water outside the bay mouth of the southern Bay with the change of gradient (Fig. 5).

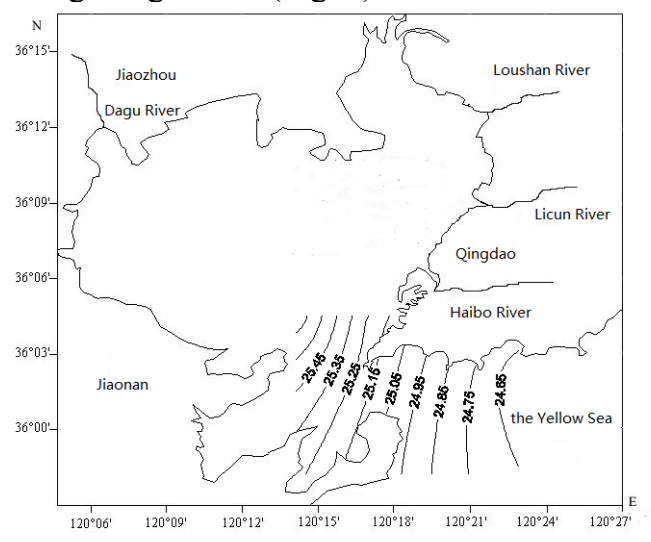

Fig.5 Temperature in the bottom water of Jiaozhou Bay in August $1980\left({ }^{\circ} \mathrm{C}\right)$

In September, high temperature $24.43^{\circ} \mathrm{C}$ appeared at Station H34 in the water outside the bay mouth of Jiaozhou Bay, and a high temperature zone formed around there with a series of parallel lines of different gradients extending from the water outside the bay mouth to the water at the bay mouth. The high temperature $24.43^{\circ} \mathrm{C}$ at the center decreased to $23.79^{\circ} \mathrm{C}$ in the water at the bay mouth of the northern Bay with the change of gradient (Fig. 6). A cryogenic water mass formed at the bay mouth.

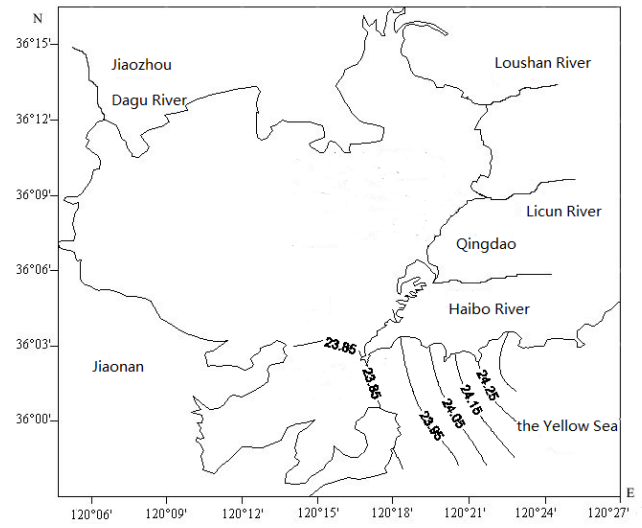

Fig.6 Temperature in the bottom water of Jiaozhou Bay in September $1980\left({ }^{\circ} \mathrm{C}\right)$

In October, high temperature ranging from $20.00^{\circ} \mathrm{C}$ to $20.04^{\circ} \mathrm{C}$ appeared at Station H34 and Station H35 in the water outside the bay mouth of Jiaozhou Bay, and a high temperature zone formed around there with a series of parallel lines of different gradients extending from the water outside the bay mouth to the water inside the bay mouth. The high temperature $20.04{ }^{\circ} \mathrm{C}$ at the center decreased to $15.53^{\circ} \mathrm{C}$ in the water inside the bay mouth of the northern Bay with the change of gradient (Fig. 7).

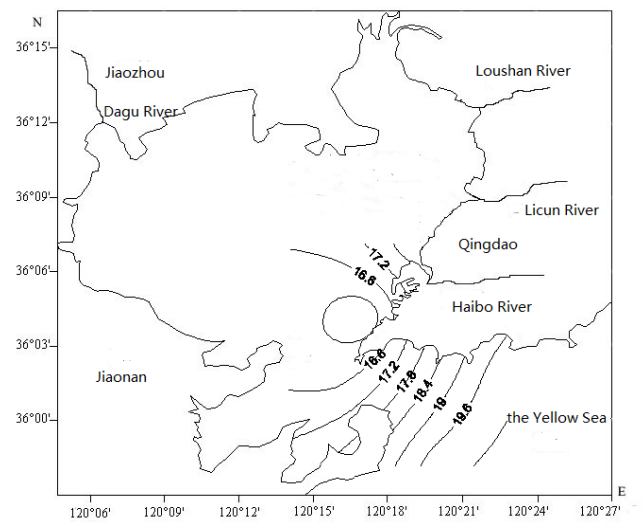

Fig.7 Temperature in the bottom water of Jiaozhou Bay in October $1980\left({ }^{\circ} \mathrm{C}\right)$

\section{Discussion}

\subsection{Variation Range of the Bottom Water Temperature}

The bottom water temperature in Jiaozhou Bay ranged at a high level between $12.35^{\circ} \mathrm{C}$ to $25.72^{\circ} \mathrm{C}$ and a low level between $10.18^{\circ} \mathrm{C}$ to $24.58^{\circ} \mathrm{C}$ in May, June, July, August, September and October. The high level was over $12.00^{\circ} \mathrm{C}$ and the low level was over $10.00 \mathrm{C}$, far higher than $0.00 \mathrm{C}$, which indicated that the bottom water temperature was moderately high. 


\subsection{Variation Trend of the Bottom Water Temperature}

The rise of water temperature is mainly caused by short-wave radiation from the sun and sky and long-wave radiation from the atmosphere, which continuously transmits heat to seawater all the year round. There is also the heat transmitted from ocean currents.

In May, June, July and August, a high temperature zone formed around the water inside the bay mouth in Jiaozhou Bay. Being relatively high, the bottom water temperature reached $12.35^{\circ} \mathrm{C}$ to $25.72^{\circ} \mathrm{C}$ and began to decrease from the water inside the bay mouth to the water outside the bay mouth in the south, thus forming a series of parallel lines of degressive gradients extending from the water inside the bay mouth to the water outside the bay mouth in the southern Bay. Thus, the bottom water temperature from May to August first increased in the water inside the bay mouth, followed by the water at the bay mouth, with the water outside the bay mouth as the end.

In September and October, the temperature at the Station H34 in the eastern coastal waters outside Jiaozhou Bay reached a high level of $20.00^{\circ} \mathrm{C}$ to $24.43^{\circ} \mathrm{C}$, and a high temperature zone formed around there. During the period, the water temperature in the bottom layer first decreased at the water outside the bay mouth, followed by the water at the bay mouth, with the water inside the bay mouth in the north as the end, thus forming a series of parallel lines of degressive gradients extending from the water outside the bay mouth to the water inside the bay mouth in the northern Bay. Thus, the bottom water temperature from September to October first increased in the water inside the bay mouth, followed by the water at the bay mouth, with the water outside the bay mouth as the end.

\subsection{Cryogenic Water Mass in the Bottom Water Outside the Bay mouth}

In September, the temperature at the Station H34 in the bottom water outside the bay mouth of Jiaozhou Bay reached a high level of $24.43^{\circ} \mathrm{C}$, and a high temperature zone formed around there with a series of parallel lines of different gradients extending from the water outside the bay mouth to the water at the bay mouth. The temperature of $24.43{ }^{\circ} \mathrm{C}$ at the center decreased to $23.79^{\circ} \mathrm{C}$ in the water at the bay mouth in the northern Bay with the change of gradient (Fig. 6).

In September, the bottom water temperature in Jiaozhou Bay ranged from $23.79^{\circ} \mathrm{C}$ to $24.43^{\circ} \mathrm{C}$, and the seawater temperature was very high. In Jiaozhou Bay, the water temperature was decreasing. According to Yang Dongfang's definition of "Cryogenic Water Mass", a cryogenic water mass formed in the water at the bay mouth (Figure 8) and extended among the water inside the bay mouth-at the bay mouth-in the southern water outside the bay mouth. The temperature of this cryogenic water mass ranged from $23.79^{\circ} \mathrm{C}$ to $23.91^{\circ} \mathrm{C}$, and the interval length of the seawater temperature variation was $0.12^{\circ} \mathrm{C}$.

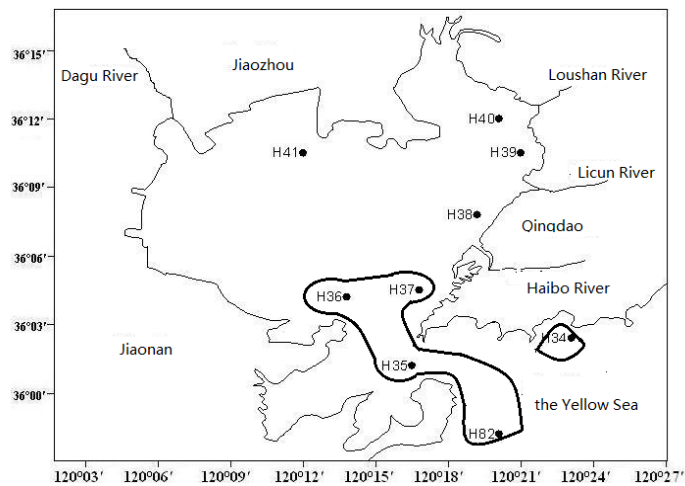

Fig.8 Temperature in the bottom water of Jiaozhou Bay in September $1980\left({ }^{\circ} \mathrm{C}\right)$

\section{Discussion}

The bottom water temperature in Jiaozhou Bay ranged at a high level between $12.35^{\circ} \mathrm{C}$ to $25.72^{\circ} \mathrm{C}$ and a low level between $10.18^{\circ} \mathrm{C}$ to $24.58^{\circ} \mathrm{C}$ in May, June, July, August, September and October, which indicated that the bottom water temperature was moderately high during this period.

In May, June, July and August, a high temperature zone formed around the water inside the bay mouth of Jiaozhou Bay, and the bottom water temperature reached $12.35^{\circ} \mathrm{C}$ to $25.72{ }^{\circ} \mathrm{C}$. From May to August, the bottom water temperature first increased in the water inside the bay mouth, followed by the water at the bay mouth, with the water outside the bay mouth as the end.

In September and October, the temperature of the eastern coastal water outside Jiaozhou Bay reached $20.00^{\circ} \mathrm{C}$ to $24.43^{\circ} \mathrm{C}$, and a high temperature zone formed around there. From September to October, the bottom water temperature first decreased in the water inside the bay mouth, followed by the water at the bay mouth, with the water outside the bay mouth as the end.

In September, the bottom water temperature in Jiaozhou Bay ranged from $23.79^{\circ} \mathrm{C}$ to $24.43^{\circ} \mathrm{C}$, and the seawater temperature was very high. In Jiaozhou Bay, the water temperature was decreasing. According to Yang Dongfang's definition of "Cryogenic Water Mass", a cryogenic water mass formed in the water at the bay mouth (Figure 8) and extended among the water inside the bay mouth-at the bay mouth-in the southern water outside the bay mouth. The temperature of this cryogenic water mass ranged from $23.79^{\circ} \mathrm{C}$ to $23.91^{\circ} \mathrm{C}$, and the interval length of the seawater temperature variation was $0.12^{\circ} \mathrm{C}$. It extended widely among the water inside the bay mouth-at the bay mouth-in the southern part outside the bay mouth.

\section{Acknowledgement}

This research was sponsored by Doctoral Degree Construction Library of Guizhou Nationalities University, Research Projects of Guizhou Nationalities University ([2014]02), Research Projects of Guizhou Province Ministry of Education (KY [2014] 266), Research 
Projects of Guizhou Province Ministry of Science and Technology (LH [2014] 7376). Thanks Prof. Qiang Shi for ardent help and nice suggestion.

\section{References}

1. Dongfang Yang. Silicon Dynamics of Earth Ecosystem [M]. Beijing: China Ocean Presss, 2013, 1-372.

2. Ming Yang, Dongxing Xia, Dongqi Gu, Zou Xue, Aiping Feng. Geographic Environmental Evolution in the Qingdao Coastal Area Under the Influence of Global Change [J]. Advances in Marine Science, 2005, 23(3): 289-296.

3. Dongfang Yang, Zhenqing Miao. Bay Ecology (Volume 1) [M]. Beijing: China Ocean Press, 2010, $1-320$.

4. Dongfang Yang, Zhenhui Gao. Bay Ecology (Volume 2) [M]. Beijing: China Ocean Press, 2010, 1-330.

5. Dongfang Yang, Zhenhui Gao, Peiyan Sun, Sheng Zhao, Youchi Zhang. Silicon limitation on primary production and its destiny in Jiaozhou Bay, China VI The ecological variation process of the phytoplankton $[J]$. Chin. J. Oceanol. Limnol. 2006, 24(2): 186-203.

6. Dongfang Yang, Zhenhui Gao, Yingbin Yang, Peiyan Sun, Xingping Wang. Silicon limitation on primary production and its destiny in Jiaozhou Bay, China VII The Complementary mechanism of the earth ecosystem [J]. Chin. J. Oceanol. Limnol. 2006, 24(4): 401-412.

7. Dongfang Yang, Zhenhui Gao, Jie Qin, Suxia Huo, Zhongqiang Li. Complementary Mechanism of Nutrient Silicon in Earth Ecosystem [J]. Advances in Marine Science, 2006, 24 (4): 407-412.

8. Dongfang Yang, Zhenhui Gao, Yuan Ma, Peiyan Sun, Yingbin Yang. Influence of environmental change on marine biological resources in Jiaozhou Bay [J]. Marine Environmental Science, 2006, 25 (4): 39-42.

9. Dongfang Yang, Jianping Wu, Yanfeng Qu, Jun $\mathrm{Hu}$, Yanrong Zhou. Complementary Mechanism of Air and Water Temperatues in the Earth Ecosystem [J]. Advances in Marine Science, 2007, 25 (1): 117-122.

10. Dongfang Yang, Zhenhui Gao, Wenfeng Li, Zijiang Yu, Changjiang Huang. Study on the Impact of Marine Ecological Change on Climate and Its Associations with Crop Planting [J]. Journal of Modern Academic Research, 2007, 7:104-109.

11. Dongfang Yang, Y CHEN, Z H GAO, et al. SiLicon Limitation on primary production and its destiny in Jiaozhou Bay, China IV transect offshore the coast with estuaries [J]. Chin. J. Oceanol. Limnol. 2005, 23(1): 72-90.

12. Dongfang Yang, Fan Wang, Zhenhui Gao, et al. Ecological Phenomena of Phytoplankton in Jiaozhou Bay [J]. Marine Science, 2004, 28 (6): 71-74.

13. State Oceanic Administration. The Specification for
Marine Monitoring [Z]. Beijing: China Ocean Press, 1991. 